\title{
2 \\ Development of
Same-Sex Attracted Youth
}

Ritch C. Savin-Williams and Kenneth M. Cohen

\section{Construction of "Gay Youth"}

\subsection{The Beginnings}

Although youthful homoeroticism has been documented by artisans, poets, and historians for thousands of years, it was not until the early 1970s that American scientists-primarily medical researchers and mental health professionals-began systematically studying a newly recognized clinical group they classified as "gay youth." Casting doubt on earlier interpretations that adolescent same-sex encounters were experimental events that were temporary derailments from inevitable heterosexuality, they acknowledged that these youth comprised a unique grouping with their own exceptional experiences, needs, and risks. Not surprisingly, early sources of information about gay youth were comprised mostly of the adolescents who investigators could unquestionably identify and entice to participate in gay research: male prostitutes, runaways, and delinquents. Their early findings consequently highlighted the lives of specific adolescents who were, by definition, in physical, psychological, and social peril.

As information accumulated from studies drawn from similar populations, the accepted portrait of gay youth narrowed to a simplistic, monolithic life representation. These depictions warned that adolescents necessarily suffered miserable, rejected, and risk-filled existences. Dissemination of this "truth" through mental health alerts, advocacy tracts, and policy proposals achieved an intended outcome-eliciting the aid of social service and educational agencies, which created support groups and mental health guidelines (Jones, 1978; Tartagni, 1978; Coleman, 1981/1982; Malyon, 1981; Martin, 1982; Remafedi, 1985). One such agency, the Institute for the Protection of Lesbian and Gay Youth (IPLGY), was established in New York City in 1979 (Martin and Hetrick, 1988). Renamed for its founders, the Hetrick-Martin

Manuscript based in part on Savin-Williams and Cohen (2004), Cohen and Savin-Williams (2004), and Savin-Williams (2005). 
Institute and its affiliated Harvey Milk School committed themselves to addressing the heretofore ignored physical, social, educational, and therapeutic needs of gay youth. Social services and community support groups in other large urban centers (e.g., Horizons in Chicago) opened shortly thereafter. Comprising an easily identifiable population of homoerotic youth, the attendees were repeatedly tapped by investigators as a primary pool of research subjects. Drawing conclusions from a sample that was composed, by definition, of troubled and helpseeking individuals, researchers perhaps unwittingly further perpetuated a particular negative characterization of gay youth.

Few researchers at the time questioned whether these youth group members were representative or even characteristic of other youth with same-sex attractions and behavior. The mere fact that any gay teenagers were located was itself cause for celebration and publication. For example, the first empirical study included 60 young men, many of whom were Seattle hustlers (Roesler and Deisher, 1972). Predictably, many recounted high numbers of sexual encounters, with one young man logging 3000+ partners. Furthermore, many participants had visited a gay bar, and nearly half had sought mental health counseling. These boys perceived homosexuals as inherently distraught, desperate misfits because of their homosexuality and the stereotyped life script they were destined to follow. Many were suicidal, lived on the fringes of society, and felt rejected and disdained. These youth needed rescuing, and researchers advocated for them with data highlighting societal contributions to their destitute lives.

Subsequent research explored the social stressors that placed gay (male) youth at high risk for physical and psychological problems (Remafedi, 1987a,b). Indeed, most participants reported emotional difficulties, poor grades, school truancy, and substance abuse. Many had consulted a psychiatrist or psychologist. Almost one in two had contracted a sexually transmitted infection, had committed a crime, or had run away from home; and nearly one in three had attempted suicide and had been hospitalized for psychological difficulties. Most of the other youth reported that they would likely attempt suicide in the future. Despite this morbid profile, Remafedi concluded that it was "unlikely" that his adolescent sample was biased because "the very experience of acquiring a homosexual or bisexual identity at an early age [adolescence] places the individual at risk for dysfunction" (Remafedi, 1987a, p. 336). Similarly, after identifying numerous mental health problems (e.g., suicidality) and a history of running away, unsafe sexual behaviors, and drug use among IPLGY clientele, another research team concluded that there was "no evidence that the agency attracts primarily troubled youth" (Rotheram-Borus et al., 1995, p. 77).

The legacy of these research efforts left an indelible impression on health care providers, educators, parents, and youth: Being young, gay, and troubled were intrinsically linked. One positive outcome was that as mental health professionals became increasingly sensitized to the needs of these disenfranchised teenagers who often led challenging lives, vital attention and support were provided. Research data were embraced to buttress arguments for the inclusion of gay youth in serv- 
ices provided by physicians, therapists, and educators. One clinician implored mental health professionals to help gay youth to transcend their "impoverished socialization" so they can adjust "to a stigmatized identity [that] is inherently problematic" (Malyon, 1981, p. 321). Similarly, an early sexologist argued that therapists should "assist homosexual individuals to recognize and accept their sexual identity, improve interpersonal and social functioning, and value and integrate this identity while living in a predominantly heterosexual society" (Coleman, 1981/1982, p. 42).

\subsection{Methodologic Problems}

There were other ways in which gay youth were marginalized and thus removed from mainstream developmental considerations. Even as journal articles about gay youth substantially increased from several during the 1970s to almost 40 during the 1980 s to more than 120 during the 1990s (Ryan, 2000), few of the early empirical investigations were published in prestigious, peer-reviewed social science journals or cited in adolescent textbooks. Reasons for this exclusion from adolescent behavioral scholarship were likely the following:

1. Early studies failed to meet the stringent methodologic requirements of scholarly research; were based on flawed research designs; and sampled small, usually biased, populations of help-seeking youth.

2. Manuscripts were likely to be rejected by journal reviewers and editors, who believed that preadult homoeroticism did not exist or was a transient, experimental phase.

3. Researchers did not submit manuscripts to top-tier journals because they feared that their scholarship would not be respected or judged with dispassion.

4. Most of the researchers were physicians and clinicians who submitted their work to specialty journals beyond the usual purview of mainstream social and behavioral scientists.

5. Some of the most innovative research was produced by graduate students who shunned publishing their findings because they feared being labeled a "gay researcher" or because they pursued nonacademic, often clinical vocations.

In defense of the early heroic research efforts, access to gay youth was severely limited to a fraction (the homeless, hustlers, "sissy boys") of this largely invisible population. Investigators and clinicians who recognized these methodologic limitations justifiably reasoned that to present any information on gay youth was a worthy achievement. Indeed, research-generated guidelines for health care practitioners and policyoriented recommendations regarding the treatment of gay youth proved invaluable in elevating public and professional awareness of these young people. However, the generalizability of the research findings and clinical insights to the much larger population of nongay-identified, invisible youth with same-sex attractions who did not volunteer for these early studies was rarely considered inappropriate. 
Although later investigators claimed to reduce sample bias drastically by soliciting school-based populations across numerous states (DuRant et al., 1998; Faulkner and Cranston, 1998; Garofalo et al., 1998, 1999; Remafedi et al., 1998), it is almost certain that most same-sex attracted youth remained unwilling to endorse the socially stigmatized identity label "gay," even on anonymous questionnaires. As a result, even though these studies corrected some of the methodologic problems of earlier research, they too failed to elicit a representative or even diverse sample of adolescents with same-sex attractions. The $1 \%$ to $2 \%$ of the total adolescent population who reported being gay in these studies is not likely to be orthogonal from the earlier 1980s youth participants: the "out," visible, early identifying, help-seeking teens. This nonrepresentative $1 \%$ to $2 \%$ is substantially below population estimates $(10 \%$ to $20 \%)$ of young adults who have some degree of same-sex attractions (Savin-Williams, 2005).

Investigators were, however, beginning to sample from broader venues and were thus recruiting ethnically diverse teenagers, young women, bisexuals, and international gays (e.g., Australia, Brazil, England, France, Mexico, Sweden). Youth populations were solicited from a range of public settings, including gay community picnics, collegiate meetings, friendship networks, and activist conferences. Research efforts were also being directed less to psychosocial stressors and psychopathology and more to normative developmental milestones. Similar to heterosexual youth, it was shown that gay youth experienced sexual attractions and behaviors starting at an early age, talked to friends and parents about their sexuality, and established committed romantic relationships (Herdt, 1989; Savin-Williams, 1990; D'Augelli, 1991; Herdt and Boxer, 1993).

Because most studies, including these later investigations, included only youth who freely volunteered for gay-specific research, little is known about teenagers who have same-sex attractions but who, for unknown reasons, do not willingly participate. In addition, populationbased (e.g., school) investigations that sample youth of all sexual orientations provide limited information because they fail to elicit gay identity labels from many homoerotic youth. Both gay-specific and population-based investigations do not adequately sample the full range of same-sex attracted youth. The reasons are overlapping. Particularly in the former studies, nonparticipating youth may be unaware or uncertain of their sexuality, perhaps because they have not yet had a sexual experience (the proof). Also, they may not volunteer for the same reasons others do not participate in scientific sexuality studies: They have little sexual experience, hold traditional sexual attitudes and beliefs, have low levels of sexual sensation-seeking (low sexual libido), and excessively self-monitor their expressive (e.g., sexual) behavior (Wiederman, 1999). Among the latter population-based studies, participating but nondisclosing homoerotic youth may be reluctant or unwilling to assume a socially stigmatized identity label during adolescence. Nondisclosure may also reflect personal or political resistance to being categorized or defined by their sexuality (Savin-Williams, 2005). The consequence of these limitations is that little is known about homo- 
erotic persons "who are not linked, either superficially or strongly, to the gay world" (Sandfort, 1997, p. 265, emphasis added). Accordingly, caution is advised when appraising the scientific merit of research on gay youth (Boxer and Cohler, 1989; Savin-Williams, 1990).

Despite this limited research foundation, general consensus exists regarding the lives of same-sex attracted youth. This information is ordered here according to the average age of acquired developmental milestones. After addressing the elusive issue of estimating the prevalence of youth with same-sex attractions, we review that which is known about early feelings of differentness, the onset of same-sex attractions, initial indications one might not be heterosexual, first sexual experiences, the recognition (self-label) of homosexuality, and the disclosure of this information to others.

\section{Prevalence of Gay Youth}

The number of youth with same-sex attractions far exceeds those who engage in same-sex behavior or who identify as gay. This fact is consistent with the findings of a national study of adults in which the proportion of individuals with same-sex attractions (8\%) was far greater than the fraction who identified as gay, lesbian, or bisexual $(2 \%)$ and was slightly higher than those who engaged in same-sex behavior $(7 \%)$ (Laumann et al., 1994); these findings are congruent with data from other countries (Sell et al., 1995). In early investigations of youth, discrepancies among these domains of same-sex sexuality (attractions, identity, behavior) were also evident. For example, whereas nearly $5 \%$ of youth in a school-based study reported same-sex fantasies or had predominant same-sex attractions, slightly more than $1 \%$ had same-sex behavior or a sexual identification (Remafedi et al., 1992). Indeed, most anonymous surveys of representative samples of U.S. adolescents reveal that fewer than $2 \%$ identify as gay/bisexual (Garofalo et al., 1999). The propensity toward greater same-sex attractions than sexual identification has also been observed in other countries (van Griensven et al., 2004).

Recent surveys of adolescents and young adults document significantly higher prevalence rates for same-sex attractions, behavior, and identity, although the discrepancies among them remain. Eleven percent of students at one high school self-ascribed one or more attributes of a same-sex sexuality, whereas fewer than 3\% identified as gay (Orenstein, 2001). In another high school sample, 6\% acknowledged that they "know that I am homosexual or bisexual" and an additional $13 \%$ "frequently or sometimes wonder" if they are homosexual (Lock and Steiner, 1999). Among college students, $10 \%$ of males and $12 \%$ of females reported "neutral" to "strong" attractions to members of the same sex, two to four times as many as those who identified as gay/bisexual (Lippa, 2000).

Self-identified gay youth could conceivably represent as little as $10 \%$ of all youth who have same-sex attractions or who engage in same-sex behavior. Whether these adolescents differ from nongay-identified 
homoerotic youth in important ways remains unknown. So long as research participation necessitates identifying oneself as gay, investigators will overlook many youth who ultimately identify as gay after adolescence and nearly all who will never identify as gay but who nonetheless have a homoerotic orientation.

Before proceeding to a discussion of typical developmental milestones among same-sex attracted youth, several cautionary notes must be advanced. First, despite the seemingly continuous progression of developmental milestones that are based on the average age for reaching particular events, same-sex development does not proceed in an orderly, invariant, or universal manner or occur within a set, or even typical, time frame (Savin-Williams, 2005). For example, although most adolescents self-identify as gay or bisexual prior to disclosing this information to others or dating a same-sex partner, some youth enter a committed romantic relationship before self-labeling. Unlike previous cohorts of gay men, an equal proportion of contemporary young men recognize that they are gay before engaging in homoerotic sex as after (Dubé, 2000). Whereas it is typical to recollect initial same-sex attractions prior to pubertal onset, it is not uncommon for attractions to first surface in high school. Indeed, the variability among developmental milestones is so large that in one study the age range among all 10 identified milestones overlapped (Floyd and Stein, 2002). Thus, sweeping assumptions about "normal" or "typical" developmental trajectories should be rejected.

Second, the unfolding of homoerotic development has been deeply influenced by the sexual revolution that has both normalized and destigmatized same-sex sexuality, particularly among youth. One consequence has been an accelerated evolution in which developmental cohorts, or generations, transform every 5 years and contain greater intragroup variability than during any preceding era (Savin-Williams, 2005). The increasing acceptance of sexual diversity and mainstreaming, rather than ghettoizing, homoeroticism have allowed contemporary cohorts of same-sex attracted youth to incorporate and express life-styles, perspectives, and languages that are similar to those embraced by heterosexual youth. Stereotypes have dwindled as gay youth increasingly reveal that they vary among themselves in much the same way as heterosexual youth vary-shaped more by their gender, ethnicity, physical attributes, personality, and economic class than by their sexuality. Thus, it is essential to acknowledge that past research on gay youth development has limited generalizability to today's same-sex attracted teens. The findings recounted below may better serve as guideposts than definitive maps.

\section{Feeling Different}

Research frequently documents that gay adults recall growing up feeling different from same-sex peers. However, many nongay children also feel estranged, and many children who eventually identify as gay do not feel different. Furthermore, children of all sexual orientations 
may feel different because of their physical appearance, race/ethnicity, religious affiliation, personality characteristics, or sex-atypical motor behavior rather than because of their sexuality. One investigation found that regardless of sexual orientation, only a small number of adults, about one in five, recalled feeling "not at all" different from childhood peers (Bell et al., 1981). Among the remaining participants, gays were three times more likely than heterosexuals to feel "very much" different as children, and they more often felt dissimilar primarily because of their sex-atypical behavior and interests. However, nearly one-fourth of heterosexual men also felt different due to their low interest in masculine sports. A second major reason for feeling different, reported by one in five lesbians and gays but only 1 in 50 heterosexuals, was undeniable homoerotic interest and heteroerotic indifference.

Additional research confirmed that gay adult recollections of marginalization were predominantly related to personality variables and behavioral sex atypicality rather than libidinal desires per se (Troiden, 1979). Almost half of the adult gay men attributed their initial feelings of differentness to gender inadequacies, effeminacy, and lack of masculine interests. Other reasons included general alienation and experiences of warmth and excitement in the company of males. Most asserted that their "inappropriate" sexual longings were less influential than the shame associated with gender ineptitude. Children seemingly develop awareness of the ways in which members of their sex are supposed to act at an earlier age than they come to understand what it means to be gay or straight. By their teenage years, however, $99 \%$ of the homoerotic men reported that they had come to feel sexually different because of erotic interest in boys, diminishing or absent sexual longings for girls, and same-sex sexual activities with peers. Adult lesbians share similar developmental memories. Whereas $75 \%$ felt different, only half attributed this distinction to their sexuality (Schneider, 2001).

In a youth-based study, the mean age of first feeling different among gay youth was 8 years (D'Augelli and Grossman, 2001). Half of all boys and two-thirds of all girls remembered being called sissy or tomboy, respectively. Just over half reported that they had been directly told by others that they were different, and about one-third recalled that at around age 10 or 11 their parents had attempted to prevent them from behaving like a sissy or tomboy. Thus, although many homoerotic youth feel at odds with peers for reasons common to other adolescents (e.g., appearance, abilities), they are more likely to identify sexatypical behavior and interests, including same-sex attractions, as a basis for their feelings of estrangement.

\section{Same-Sex Attractions}

Investigators frequently propose that the manifestation of same-sex attractions is the earliest and most reliable predictor of adult homosexuality. Across studies there is considerable diversity in the age of 
reported first same-sex attractions, from the very first memories onward. Furthermore, averages have been steadily declining over the last four decades, especially among girls, closing the gap between the sexes. This ongoing diminution among successive cohorts in recognition of homoeroticism cannot be attributed to an earlier pubertal onset but to cultural shifts in awareness of same-sex attractions. Labels and meanings have been given to previously unspecified and seemingly inconsequential desires (Knoth et al., 1988; Rosario et al., 1996; SavinWilliams and Diamond, 2000, 2004; Baumeister et al., 2001).

Regardless of these cohort changes, boys usually report becoming cognizant of their same-sex erotic interests and impulses at an earlier age than do girls. This is not because boys are sexual and girls are not but because the eroticism girls recall is usually thought to be romantic rather than physical. Girls' greater attention to romanticism is related to the greater extent to which they are erotically aroused by psychological rather than physical stimulation (Kinsey et al., 1948, 1953), a trend no doubt reinforced by cultural values. Girls do, however, engage in sexual behavior such as petting and masturbation, but these activities are only minor manifestations of their first erotic arousal. Later research confirmed this sex difference: Girls are more likely to recall their first same-sex attraction as an emotional attachment or crush, whereas boys recall a sexual thought, arousal, or behavior (Herdt and Boxer, 1993).

These sex differences support the hypotheses that female sexual attractions are more contextual than male attractions and more dependent on interpersonal relationships. Central for young women is the desire to form pair bonds, for romantic intimacy, and for emotional responsiveness (Weinberg et al., 1994; Golden, 1996; Peplau et al., 1999). The origin of these sex differences remains uncertain and raises fundamental questions about the relative roles of biology and environment. One uncontested fact is that, relative to male sexuality, female sexuality is considerably more responsive to cultural and social factors, more subject to change in response to external circumstances, and more variable within a particular life course (Baumeister, 2000; Diamond, 2003b).

Several research findings raise questions about portraying the onset of same-sex attractions as necessarily the earliest or best developmental indicator of gayness. First, quite often same-sex attractions do not proceed but are contemporaneous with other developmental milestones, such as feeling different, first sex, or first romance. Second, some heterosexuals, especially females, experience same-sex attractions. Across cultures, girls are less likely than boys to have exclusive heterosexual attractions (Storms, 1981; Rosario et al., 1996; Hillier et al., 1998). Third, most gay youth experience opposite-sex attractions, sometimes prior to same-sex attractions. In several studies, more than $80 \%$ of same-sex attracted girls and $60 \%$ of the boys acknowledged opposite-sex attractions, fantasies, and/or arousals; in addition, boys reported the onset of heterosexual attractions at the same age, on average, as same-sex attractions-a year or two earlier than girls (Rosario et al., 1996; Savin-Williams, 1998; D'Augelli and Grossman, 
2001). Two thirds of adult heterosexual females and nearly half of adult lesbians in another study reported romantic/sexual attractions counter to their sexual orientation-at 18 years for heterosexual females but at 13 years for lesbians (Pattatucci and Hamer, 1995). That lesbians report attractions counter to their sexual orientation at an earlier age could represent cultural pressure to conform to social expectations, leading some girls to recognize or perhaps misinterpret heteronormative feelings. Alternatively, it may represent authentic attractions to both females and males. For both sexes, sexual/romantic attractions consistent with one's sexual orientation appear to emerge first, prior to or during early pubertal development, whereas attractions that are inconsistent surface later, following pubertal onset.

Early sexual attractions are relatively unrelated, however, to the timing at which same-sex attracted young adults eventually self-label, disclose to others, enter a romantic relationship, or experience a positive or negative same-sex identity. Whether the attractions are general or specific, emotional or sexual, they are similarly unrelated. They appear to stand alone; they are highly personally significant but not necessarily connected to subsequent aspects of a youth's sexuality. It remains empirically unknown why some youth with same-sex attractions do not identify as lesbian or gay, although it is conceivable that those who do identify may experience same-sex attractions with greater frequency or intensity (Savin-Williams, 2005).

Regardless of the specific memory of same-sex attractions or its timing, most youth recount that they were not troubled by their early homoeroticism because it felt natural, pleasurable, and mysterious (Savin-Williams, 2005). Eventually, however, a significant number of youth question the meaning of their homoeroticism.

\section{Doubting One's Heterosexuality}

Simultaneously or years after the onset of same-sex attractions, some youth begin to entertain the notion that they are not heterosexual. They question the implications of their homoerotic attractions or behavior for their adult sexual status. Most homoerotic youth recall same-sex attractions, fantasies, and arousal several years prior to examining the meaning of these feelings. Challenging one's assumed heterosexuality rarely occurs among preteenagers but is more often a milestone achieved during adolescence proper (Rosario et al., 1996; Frankel, 2003). The process can lead to rejection or acceptance of a sexualminority identity label.

Some youth report they never had such a phase because they immediately understood the meaning of their homoeroticism. The most common precursors to questioning among females in several studies were awareness of same-sex attractions, encounters with a facilitating environment (e.g., peer conversations, university courses, movies), or an exceedingly intimate, emotional same-sex bond (Savin-Williams and Diamond, 2000; Diamond, 2003a,b; Savin-Williams, 2005). Males usually first doubted their heterosexuality subsequent to homoerotic 
arousal or same-sex sexual experiences, unusually low heterosexual libido, or same-sex romantic crushes (Troiden, 1979; Hillier et al., 1998; Savin-Williams, 1998).

The fact that some youth interpret their homoerotic experiences as a phase or normal experimentation may prevent them from immediately progressing from sexual questioning to gay identification. Others may need further evidence before self-defining because they have not yet had gay sex or they believe that they do not act "stereotypically gay." However, sex as a testing ground for a gay identity is increasingly becoming a relic of previous generations (Dubé, 2000).

\section{Same-Sex Behavior}

A same-sex encounter can be the earliest, intermediate, or final milestone. Indeed, among contemporary cohorts of same-sex attracted youth, approximately $5 \%$ to $10 \%$ of boys and $20 \%$ of girls identify as gay without having had gay sex. By contrast, most of the youth who engage in gay sex do not identify as gay; some do not even acknowledge their same-sex attractions (Savin-Williams, 1998, 2005). A recent review of the empirical literature concluded that some homoerotic youth are not sexually active (heterosexually and homosexually virgins), that some homoerotic youth are same-sex virgins but heterosexually experienced, that some heteroerotic youth have gay sex, that most homoerotic and an unknown number of heteroerotic youth have both homosexual and heterosexual sex, and that some youth only have sexual encounters consistent with their sexual orientation (Savin-Williams, 2005).

Challenging popular beliefs in childhood sexual latency, Kinsey and colleagues $(1948,1953)$ demonstrated that humans are naturally sexual throughout childhood. Sex play was a source of erotic arousal for both sexes, consisting of genitalia exhibition, examination, and mutual manipulation among peers. Accessibility to same-sex peers facilitated widespread homosexual encounters, which declined dramatically with age due to repressive socialization that caused heterosexually conditioned adolescents to renounce same-sex behavior. By age 20 years, 17\% of women and $37 \%$ of men had had at least one homosexual experience to the point of orgasm. Altogether, $10 \%$ of boys and $2 \%$ of girls were judged almost entirely or exclusively homosexual in overt sexual activities by age 15 . Recent research documents a lower percentage of the population engages in same-sex behavior: Approximately 3\% of British, Greek, and U.S. adult and adolescent populations had a history of same-sex activities (Garofalo et al., 1999; Papadopoulos et al., 2000; Copas et al., 2002). Diamond's (1993) cross-cultural review concluded that $2 \%$ to $3 \%$ of females and $5 \%$ to $6 \%$ of males had engaged in homoerotic behavior since the onset of adolescence.

Nonetheless, most of the adolescents and young adults with samesex behavior identify as heterosexual and most of the gay/bisexual males (averaging 60\%) and lesbian/bisexual females (averaging 80\%) are heterosexually experienced (Remafedi et al., 1992; Garofalo et al., 
1999; Savin-Williams, 2005). Thus, only a small proportion of gayidentified youth engages solely in homoerotic behavior and some homoerotic youth (especially females) have significantly more opposite-sex than same-sex encounters (D'Augelli, 1991; D'Augelli and Hershberger, 1993; Hillier et al., 1998). These data imply that neither preadult opposite-sex nor same-sex behavior necessarily predicts heterosexual or homosexual identification. These "aberrations" are most likely to occur under the pretense of adolescent or young adult "experimentation" when same-sex encounters "mean" the least (Diamond, 1993).

Although adolescents of all sexual orientations seemingly share same-sex experiences, there are notable differences in the extent to which particular youth consistently and fervently pursue homoerotic encounters, the significance they ascribe to same-sex and opposite-sex behavior, and the emotional and physical satisfaction derived from these interactions. For example, in contrast to heterosexual or bisexual youth, opposite-sex activities may be mandatory and yet relatively unappealing to gay youth. A comparative investigation of young women's sexual experiences found that the degree, proportion, and level of sexual arousal and behavior most differentiated homoerotic from heteroerotic women. The former had sex with men, but they had it less often, had it later, and enjoyed it less than did the heteroerotic women (Goode and Haber, 1977). Similarly, compared to heterosexual youth, gay-identified and bisexual-identified male youth reported far more homoerotic contact, by ratios of nearly $40: 1$ and $20: 1$, respectively, as well as fewer opposite-sex experiences (Remafedi et al., 1992; DuRant et al., 1998; Garofalo et al., 1999). Whereas having many samesex partners best predicted homoerotic orientation among males, the only significant predictor of future identity among females was initial greater relative proportions of same-sex to opposite-sex attractions (Diamond, 2000, 2003a,b).

The source of greatest intrapopulation variation among many studies is the subject's biologic sex. There are sex differences in the number and sequence of same-sex and opposite-sex encounters, mean age of initial sexual encounters, and context for sexual behavior (Remafedi et al., 1992; D'Augelli and Hershberger, 1993; Rosario et al., 1996; Kryzan, 1997; DuRant et al., 1998; Saewyc et al., 1998; Garofalo et al., 1999; Savin-Williams, 2005). Compared to females, homoerotic males were more likely to participate in homosexual activity and to report more same-sex partners; homoerotic females were more likely to engage in heterosexual behavior. In one study, young women had more total same-sex encounters even though they had fewer sex partners, suggesting that they may forgo casual sex in favor of frequent sexual contact with a single partner (Rosario et al., 1996).

The mean age of first sexual experience was reported in these studies to be later (adolescence proper) for females than males, resulting in fewer early sexual contacts. Males were more likely to experience a same-sex before an opposite-sex encounter, whereas females reported the reverse pattern. This likely reflects the greater incidence of girls as "invitee" rather than "inviter" in heterosexual dating/sex and the 
greater likelihood that females are genuinely attracted to both sexes. The initial opposite-sex experiences for both sexes usually occurred in the context of a dating relationship (Weinberg et al., 1994; Baumeister, 2000; Diamond, 2003b).

Contexts for first same-sex sexual behavior also reveal sex differences. Most young women (two thirds in one study) had their initial same-sex contact within a friendship or dating relationship (Herdt and Boxer, 1993). Whereas one-third of males also preferred "relationship sex," their most common first context was a purely sexual encounter. Overall, females are more likely than males to attach emotional and romantic meaning to their same-sex relationship prior to engaging in sexual behavior. These sex differences, however, are a matter of degree, not of kind (Savin-Williams and Diamond, 2004).

\section{Self-Identification}

"Coming out to self," or self-labeling, is perhaps the most personally significant developmental milestone. A historically recent construction (Foucault, 1978), prior to the twentieth century people seldom thought of their sexuality as a basis for their personal identity. Other historic developments are the escalating prevalence of individuals who identify as a sexual minority, the decreasing age at which this occurs, and the social visibility afforded to those who self-label. Nonetheless, despite ever-increasing numbers of self-identified gays, lesbians, and bisexuals, most of the same-sex attracted individuals have not, and likely will never, identify as gay. This issue and the increasing cultural visibility of sexual minorities are addressed elsewhere (Savin-Williams, 2005).

In the past, identification as a sexual minority occurred following adolescence, often well into young adulthood (mid-twenties). In sharp contrast, increasingly contemporary youth are self-labeling while still in high school, often by age 15 (Savin-Williams, 2005). Furthermore, fewer females than males ever label their feelings but not themselves as gay; they more often transition immediately from labeling attractions to labeling self. The developmental lag from first same-sex attractions, behaviors, and questioning to identification might span months, years, or decades and is briefer among females than males (Sears, 1991; D'Augelli and Hershberger, 1993; D'Augelli and Grossman, 2001). One study reported that the average girl required a little more than 3 years to progress from first same-sex attractions to self-labeling compared to 5 years for the average boy (Savin-Williams, 2005). Additionally, the factors that inspire adolescents to embrace a socially stigmatized label remain mostly unexamined. In one study girls credited a fascination with other girls, a same-sex romantic involvement, or a facilitative event (book, academic course, movie); boys attributed sexual thoughts, arousals, and sexual experiences (Savin-Williams and Diamond, 2000). These factors mirror those reviewed above that lead to questioning one's assumed heterosexuality. 
Although considerable research documents diversity between the sexes, few empirical investigations address variations among ethnic/ racial groups in identity formation (Ryan, 2002). Contingent on their degree of enculturation into mainstream society and their corresponding identification and immersion into their own ethnic culture, young Latinos, Asians, and African Americans face "social suicide" if they adopt an identity closely associated with White decadencehomosexuality (Manalansan, 1996; Savin-Williams, 1996). Because homosexuality is characterized by some ethnic groups as a White disease, identifying as homosexual is interpreted as a rejection of one's ethnic community. Thus, compared to Whites, it would be expected that these youth would identify at later ages. However, the limited empirical evidence does not support this conclusion. Among college men, Latinos were aware of their same-sex attractions at an early age and Asian Americans engaged in sex at a late age. Yet, compared to the total sample, both groups self-labeled as gay/bisexual at about the same age, 15 to 16 years (Dubé and Savin-Williams, 1999). African American young men were less likely than White men to label their same-sex feelings and behavior as gay, but those who did self-labeled at the same age as Whites (Edwards, 1996; Dubé and Savin-Williams, 1999). Reluctance to self-identify is particularly prevalent among African American men who are on the "down low," highly masculine, secretive, gay identity-rejecting individuals who engage in overt heterosexual and covert homosexual behavior within a context of a heterosexual identity (Denizet-Lewis, 2003). Native American Indian youth were less likely than Whites to identify as exclusively heterosexual and more likely to label themselves as bisexual or homosexual, consistent with cultural norms regarding the fluidity or flexibility of gender and sexuality (Saewyc et al., 1998).

Bisexuals, especially females, comprise a sizable portion of most studies and generate further intrapopulation variability. In extensive reviews of the empirical literature, Rodríguez Rust (2000, 2002) found that, in contrast to gays, bisexuals tend to recall heteroerotic before homoerotic attractions, perhaps reflecting memory bias for socially sanctioned sexuality. They are less likely than gays to maintain a consistent sexual identity and thus tend to reach developmental milestones at later ages. Over time, bisexuals often gravitate toward involvement with one sex only and to have fewer same-sex partners than gays but not necessarily fewer other-sex partners than heterosexuals.

Although the empirical data are scant, contemporary youth appear to be more fully embracing bisexuality and other nontraditional expressions of sexuality, including sexual fluidity, gender-based sexual categories, and identity refusal. The only prospective study of sexual fluidity among same-sex attracted young women found frequent changes in identity over 8 years (Diamond, 1998, 2000, 2003a). Most $(63 \%)$ women transitioned among several identities from childhood through young adulthood, with many considering their sexuality fluid (e.g., love depends on the person and not gender, labels are limiting). 
Some reclaimed a heterosexual label, whereas others dispensed with labels altogether. Notably, they were relinquishing their sexual identification, not their sexual orientation (attractions to women).

One implication of these findings is that because sexual identities are socially constructed and personally chosen, they might not reflect underlying biologic or psychogenic sexual orientation or match previous and ongoing sexual contact. Thus, research designs that operationalize sexual identity in a unidimensional, fixed, limited, forced-choice manner omit most of the homoerotic youth who assume unspecified sexual identities (e.g., two-spirit, boydyke, omnisexual, trans-boi), bridge multiple identities (e.g., bi-lesbian, half-dyke), claim no sexual label (e.g., unlabeled, "I love Jen"), and remain fluid in their sexuality. These individuals remain undetectable to investigators who depend on self-identifying populations.

Researchers, however, do not yet understand the reasons some youth acknowledge their same-sex attractions yet fail to self-ascribe a sexual identity label or whether this incongruence reflects sexual developmental delay or rejection of sexual classification schemes. SavinWilliams (2005) postulated several practical, philosophical, and sexual explanations for this inconsistency. For some individuals, sexual attractions and desires may be especially broad and thus transcendent of any single sexual identity category. Others forgo sexual-minority selflabeling for cultural reasons, such as unwillingness to risk or invite rejection by religious institutions or conservative ethnic or cultural affiliations. Still others eschew identification because they repudiate social or political definitions of what it means to be gay or believe prevailing sexual labels are excessively simplistic or reductionistic to represent the magnitude of their sexuality. Sexual categories unnecessarily condense a complex aspect of the self, which some youth believe is less relevant than other facets of their identity (e.g., ethnicity, career, religion). Thus, youth may conclude that they have same-sex attractions and behavior but that they are not "gay."

\section{Disclosure}

The disclosure of one's homoeroticism is often an arduous and protracted process. The endpoint of complete revelation may never be reached as new individuals who are naive about a youth's same-sex sexuality continually enter a youth's life. The process of "coming out" to others is thus seldom a single event but requires vigilance and persistence; individuals must constantly negotiate their ambivalence about the extent to which they want others to know about their sexuality. Whereas coming out can generate ridicule that imperils a youth's physical and psychological safety, it can also enhance personal integrity, identity synthesis, and psychological health-although the latter is of some dispute (Cohen and Savin-Williams, 1996). Few researchers have explored other essentials of this milestone, including disclosure outcomes and the people to whom it is most important and most difficult to disclose. 
Disclosure to others can immediately follow self-disclosure, or it may be deferred for years or decades, though the average interval between the two milestones is 1 to 2 years for boys and somewhat less for girls. It is especially noteworthy that many contemporary adolescents disclose while living at home. The first person told is usually a best friend, often a female, and increasingly, as more gay youth are visible, another same-sex attracted peer. Rarely told first are parents, extended family members, and health care or pastoral care professionals. Despite stereotypes, the reaction received from the first disclosure to a friend or sibling is usually positive, and to parents, more accepting than rejecting (Savin-Williams, 1990, 1998, 2001a).

Incentives and deterrents for coming out to others are inadequately understood. Motivations for not disclosing include fear of negative reprisals, fear of the unknown, desire not to hurt or disappoint others, and wish for privacy (Savin-Williams, 1998). Impetus for disclosing can be fueled by a desire to preserve or intensify a friendship-either by augmenting communication and trust or by attenuating miscommunication, especially if the potential recipient of the disclosure is an opposite-sex peer thought to have romantic or sexual interest in the youth. Other reasons for coming out are to elicit sympathy and acceptance, to determine whether the recipient of the news is similarly homoerotic and/or interested in a sexual or romantic relationship, to compel oneself to be more sexually honest, to relieve the stress of maintaining a shameful and potentially dangerous secret, and to make a political statement.

It is particularly noteworthy that many youth postpone coming out to parents, the likely consequence of its developmental importance (signifying a commitment to homoerotic sexuality) or dreaded outcomes (fearing rejection and homelessness) (Savin-Williams, 2001a). However, adolescents are increasingly coming out to a parent (usually the mother) while living at home and only infrequently receive a severely negative response. Reasons to disclose to parents are mostly unknown but include internal factors (e.g., mounting comfort with one's sexuality) and external factors (e.g., escalating desire for a homoerotic romantic relationship). In one study, most youth disclosed to parents because they longed to share this aspect of themselves or because a parent, unable to ignore the many subtle and blatant gestures by the child, directly inquired (Savin-Williams, 2001a). Parents responded with a range of reactions, from celebration to rejection, but most eventually accepted what many had suspected for years.

\section{Acceptance}

Developmental pathways from first feeling different or recognizing same-sex attractions to eventually accepting a same-sex sexuality are seldom linear or universal. Neither is it necessarily the case that milestones, such as coming out to self and others and feeling positive about one's identity, are inevitably linked. For example, one qualitative study found that many adolescents felt positive about their sexuality the same 
year they identified as homosexual, some felt good before they identified, and some felt fine but never identified (Sears, 1991).

Most investigations report that participants recount feeling good about their sexuality and their identity, although this may be the consequence of biased research samples in which only happy youth volunteer or report a homoerotic identity. In several studies, 75\% of adolescents reported feeling very good, good, or okay/indifferent about being gay; fewer than 10\% wished they were not gay (Kryzan, 1997, 2000; Hillier et al., 1998; D'Augelli and Grossman, 2001). These data contradict research documenting the supposed ubiquity of suicidality among gay youth (reviewed in Savin-Williams, 1994, 2001b; Savin-Williams and Ream, 2003). Young women are usually more positive than young men about their sexuality and develop this attitude at a younger age, perhaps because they experience less sexual orientation victimization, including verbal harassment, physical abuse, and sexual abuse (D'Augelli and Grossman, 2001; Savin-Williams, 2001b).

\section{Conclusions}

Since the "construction" of the gay youth during the 1970s, considerable research has focused on their mental health status and, to a lesser extent, their developmental trajectories. The accumulated findings present two significant limitations. First, the issues addressed have been restricted to "negative" life scripts. Indeed, according to one recent review, topics most frequently published have been related to gay youth's poor physical and sexual health, counseling and mental health, risky behaviors, (poor) school performance, and (no) family support (Ryan, 2000). This focus on pathology has tainted the perception of same-sex attracted youth, characterizing them as necessarily troubled individuals destined to lead sad, risky lives.

A second constraint on our knowledge has resulted from reducing youth samples to a narrow band of individuals: those who volunteer for gay research or who identify as gay in sexual research. This subset of homoerotic individuals certainly deserves attention, as many undergo unique experiences that place their health in jeopardy. However, they should not be recognized as "typical" lest they eclipse the needs and challenges of the broader community of same-sex attracted youth who are strong and resilient. The challenge of future research is identifying and sampling this larger population from which more representative conclusions can be drawn. Until such time, research on "gay youth" must be interpreted with caution.

The start of the twenty-first century has seen prolific increases in gay youth research and exposure. The media is increasingly celebrating their culture and characterizing them as any youth (i.e., the girl/boy next door). Charting their development by identifying and describing milestones is one way in which their presence is validated and normalized. It escorts them into the realm of "human development" rather than child development gone awry. 


\section{References}

Baumeister, R.F. (2000) Gender differences in erotic plasticity: the female sex drive as socially flexible and responsive. Psychological Bulletin 126:247-374.

Baumeister, R.F., Catanese, K.R., and Vohs, K.D. (2001) Is there a gender difference in strength of sex drive? Theoretical views, conceptual distinctions, and a review of relevant evidence. Personality and Social Psychology Review 5:242-273.

Bell, A.P., Weinberg, M.S., and Hammersmith, S.K. (1981) Sexual preference: its development in men and women. Indiana University Press, Bloomington.

Boxer, A.M., and Cohler, B.J. (1989) The life course of gay and lesbian youth: an immodest proposal for the study of lives. Journal of Homosexuality 17:315-355.

Cohen, K.M., and Savin-Williams, R.C. (1996) Developmental perspectives on coming out to self and others. In: Savin-Williams, R.C., and Cohen, K.M. (eds) The lives of lesbians, gays, and bisexuals: children to adults. Harcourt Brace College Publishing, Forth Worth, TX, pp. 113-151.

Cohen, K.M., and Savin-Williams, R.C. (2004) Growing up with same-sex attractions. Current Problems in Pediatric and Adolescent Health Care 34(10): 361-369.

Coleman, E. (1981/1982) Developmental stages of the coming out process. Journal of Homosexuality 7:31-43.

Copas, A.J., Wellings, K., Erens, B., Mercer, C.H., McManus, S., Fenton, K.A., Korovessis, C., Macdowall, W., Nanchahal, K., and Johnson, A.M. (2002) The accuracy of reported sensitive sexual behaviour in Britain: exploring the extent of change 1990-2000. Sexually Transmitted Infections 78:26-30.

D'Augelli, A.R. (1991) Gay men in college: identity processes and adaptations. Journal of College Students Development 32:140-146.

D'Augelli, A.R., and Grossman, A.H. (2001, August) Sexual orientation victimization of lesbian, gay, and bisexual youths. Paper presented at the American Psychological Association, San Francisco.

D'Augelli, A.R., and Hershberger, S.L. (1993) Lesbian, gay, and bisexual youth in community settings: personal challenges and mental health problems. American Journal of Community Psychology 21:421-448.

Denizet-Lewis, B. (2003, August 3) Double lives on the down low. New York Times Magazine, pp. 28-33, 48, 52-53.

Diamond, L.M. (1998) The development of sexual orientation among adolescent and young adult women. Development Psychology 34:1085-1095.

Diamond, L.M. (2000) Sexual identity, attractions, and behavior among young sexual-minority women over a two-year period. Development Psychology 36:241-250.

Diamond, L.M. (2003a) Was it a phase? Young women's relinquishment of lesbian/bisexual identities over a 5-year period. Journal of Personality and Social Psychology 84:352-364.

Diamond, L.M. (2003b) What does sexual orientation orient? A biobehavioral model distinguishing romantic love and sexual desire. Psychological Review 110:173-192.

Diamond, M. (1993) Homosexuality and bisexuality in different populations. Archives of Sexual Behavior 22:291-310.

Dubé, E.M. (2000) The role of sexual behavior in the identification process of gay and bisexual males. Journal of Sex Research 37:123-132.

Dubé, E.M., and Savin-Williams, R.C. (1999) Sexual identity development among ethnic sexual-minority male youths. Development Psychology 35:13891399. 
DuRant, R.H., Krowchuk, D.P., and Sinal, S.H. (1998) Victimization, use of violence, and drug use at school among male adolescents who engage in same-sex sexual behavior. Journal of Pediatrics 132:113-118.

Edwards, W.J. (1996) Operating within the mainstream: coping and adjustment among a sample of homosexual youths. Deviant Behavior Interdisciplinary Journal 17:229-251.

Faulkner, A.H., and Cranston, K. (1998) Correlates of same-sex sexual behavior in a random sample of Massachusetts high school students. American Journal of Public Health 88:262-266.

Floyd, F.J., and Stein, T.S. (2002) Sexual orientation identity formation among gay, lesbian, and bisexual youths: multiple patterns of milestone experiences. Journal of Research on Adolescence 12:167-191.

Foucault, M. (1978) The history of sexuality. Pantheon, New York.

Frankel, L.B. (2003) Do heterosexual men have a sexual identity? An exploratory study. Doctoral dissertation, Cornell University, Ithaca, NY.

Garofalo, R., Wolf, R.C., Kessel, S., Palfrey, J., and DuRant, R.H. (1998) The association between health risk behaviors and sexual orientation among a school-based sample of adolescents. Pediatrics 101:895-902.

Garofalo, R., Wolf, R.C., Wissow, L.S., Woods, E.R., and Goodman, E. (1999) Sexual orientation and risk of suicide attempts among a representative sample of youth. Archives of Pediatric and Adolescent Medicine 153:487-493.

Golden, C. (1996) What's in a name? Sexual self-identification among women. In: Savin-Williams, R.C., and Cohen, K.M. (eds) The lives of lesbians, gays, and bisexuals: children to adults. Harcourt Brace College Publishing, Fort Worth, TX, pp. 229-249.

Goode, E., and Haber, L. (1977) Sexual correlates of homosexual experience: an exploratory study of college women. Journal of Sex Research 13:12-21.

Herdt, G. (ed) (1989) Gay and lesbian youth. Harrington Park Press, New York.

Herdt, G., and Boxer, A.M. (1993) Children of horizons: how gay and lesbian teens are leading a new way out of the closet. Beacon Press, Boston.

Hillier, L., Dempsey, D., Harrison, L., Beale, L., Matthews, L., and Rosenthal, D. (1998) Writing themselves in: a national report on the sexuality, health and well-being of same-sex attracted young people. Monograph series 7. Australian Research Centre in Sex, Health and Society, National Centre in HIV Social Research, La Trobe University, Carlton, Australia.

Jones, G.P. (1978) Counseling gay adolescents. Counselor Education and Supervision 18:149-152.

Kinsey, A.C., Pomeroy, W.B., and Martin, C.E. (1948) Sexual behavior in the human male. W.B. Saunders, Philadelphia.

Kinsey, A.C., Pomeroy, W.B., Martin, C.E., and Gebhard, P.H. (1953) Sexual behavior in the human female. W.B. Saunders, Philadelphia.

Knoth, R., Boyd, K., and Singer, B. (1988) Empirical tests of sexual selection theory: predictions of sex differences in onset, intensity, and time course of sexual arousal. Journal of Sex Research 24:73-89.

Kryzan C. (1997) OutProud/Oasis Internet survey of queer and questioning youth. Sponsored by OutProud, The National Coalition for Gay, Lesbian, Bisexual and Transgender Youth and Oasis Magazine. Contact: survey@ outproud.org.

Kryzan, C. (2000) OutProud/Oasis Internet survey of queer and questioning youth. Sponsored by OutProud, The National Coalition for Gay, Lesbian, Bisexual and Transgender Youth and Oasis Magazine. Contact: survey@ outproud.org.

Laumann, E.O., Gagnon, J., Michael, R.T., and Michaels, S. (1994) The social organization of sexuality: sexual practices in the United States. University of Chicago Press, Chicago. 
Lippa, R.A. (2000) Gender-related traits in gay men, lesbian women, and heterosexual men and women: the virtual identity of homosexual-heterosexual diagnosticity and gender diagnosticity. Journal of Personality 68:899-926.

Lock, J., and Steiner, H. (1999) Gay, lesbian, and bisexual youth risks for emotional, physical, and social problems: results from a community-based survey. Journal of the American Academy of Child Adolescent Psychiatry 38:297304.

Malyon, A.K. (1981) The homosexual adolescent: developmental issues and social bias. Child Welfare 60:321-330.

Manalansan, M.F. (1996) Double minorities: latino, Black, and Asian men who have sex with men. In: Savin-Williams, R.C., and Cohen, K.M. (eds) The lives of lesbians, gays, and bisexuals: children to adults. Harcourt Brace College Publishing, Forth Worth, TX, pp. 393-415.

Martin, A.D. (1982) Learning to hide: the socialization of the gay adolescent. Adolescent Psychiatry 10:52-65.

Martin, A.D., and Hetrick, E.S. (1988) The stigmatization of the gay and lesbian adolescent. Journal of Homosexuality 15:163-183.

Orenstein, A. (2001) Substance use among gay and lesbian adolescents. Journal of Homosexuality 41:1-15.

Papadopoulos, N.G., Stamboulides, P., and Triantafillou, T. (2000) The psychosexual development and behavior of university students: a nationwide survey in Greece. Journal of the Psychology of Human Sexuality 11:93-110.

Pattatucci, A.M.L., and Hamer, D.H. (1995) Development and familiality of sexual orientation in females. Behavior Genetics 25:407-420.

Peplau, L.A., Spalding, L.R., Conley, T.D., and Veniegas, R.C. (1999) The development of sexual orientation in women. Annual Review of Sex Research 10:70-99.

Remafedi, G. (1985) Adolescent homosexuality: issues for pediatricians. Clinical Pediatrics 24:481-485.

Remafedi, G. (1987a) Adolescent homosexuality: psychosocial and medical implications. Pediatrics 79:331-337.

Remafedi, G. (1987b) Male homosexuality: the adolescent's perspective. Pediatrics 79:326-330.

Remafedi, G., Resnick, M., Blum, R., and Harris, L. (1992) Demography of sexual orientation in adolescents. Pediatrics 89:714-721.

Remafedi, G., French, S., Story, M., Resnick, M.D., and Blum, R. (1998) The relationship between suicide risk and sexual orientation: results of a populationbased study. American Journal of Public Health 88:57-60.

Rodríguez Rust, P.C.R. (2000) Bisexuality in the United States: a social science reader. Columbia University Press, New York.

Rodríguez Rust, P.C.R. (2002) Bisexuality: the state of the union. Annual Review of Sex Research 13:180-240.

Roesler, T., and Deisher, R.W. (1972) Youthful male homosexuality: homosexual experience and the process of developing homosexual identity in males aged 16 to 22 years. Journal of the American Medical Association 219(8):1018-1023.

Rosario, M., Meyer-Bahlburg, H.F.L., Hunter, J., Exner, T.M., Gwadz, M., and Keller, A.M. (1996) The psychosexual development of urban lesbian, gay, and bisexual youths. Journal of Sex Research 33:113-126.

Rotheram-Borus, M.J., Rosario, M., Van Rossem, R., Reid, H., and Gillis, J.R. (1995) Prevalence, course, and predictors of multiple problem behaviors among gay and bisexual male adolescents. Developmental Psychology 31:7585.

Ryan, C. (2000, March 15) An analysis of the content and gaps in the scientific and professional literature on the health and mental concerns of lesbian, gay 
and bisexual youth. Paper prepared for the American Psychological Association Healthy LGB Students Project.

Ryan, C. (2002) A review of the professional literature and research needs for LGBT youth of color. National Youth Advocacy Coalition, Washington, DC.

Saewyc, E.M., Skay, C.L., Bearinger, L.H., Blum, R.W., and Resnick, M.D. (1998) Demographics of sexual orientation among American Indian adolescents. American Orthopsychiatric Association 68:590-600.

Sandfort, T.G.M. (1997) Sampling male homosexuality. In: Bancroft, J. (ed) Researching sexual behavior: methodological issues. Indiana University Press, Bloomington, pp. 261-275.

Savin-Williams, R.C. (1990) Gay and lesbian youth: expressions of identity. Hemisphere, Washington, DC.

Savin-Williams, R.C. (1994) Verbal and physical abuse as stressors in the lives of sexual minority youth: associations with school problems, running away, substance abuse, prostitution, and suicide. Journal of Consulting and Clinical Psychology 62:261-269.

Savin-Williams, R.C. (1996) Ethnic- and sexual-minority youth. In: SavinWilliams, R.C., and Cohen, K.M. (eds) The lives of lesbians, gays, and bisexuals: children to adults. Harcourt Brace College Publishing, Fort Worth, TX, pp. 152-165.

Savin-Williams, R.C. (1998) “. . And then I became gay": young men's stories. Routledge, New York.

Savin-Williams, R.C. (2001a) "Mom, Dad. I'm gay: how families negotiate coming out. American Psychological Association, Washington, DC.

Savin-Williams, R.C. (2001b) Suicide attempts among sexual-minority youth: population and measurement issues. Journal of Consulting and Clinical Psychology 69:983-991.

Savin-Williams, R.C. (2005) The new gay teenager. Harvard University Press, Cambridge, MA.

Savin-Williams, R.C., and Cohen, K.M. (2004) Homoerotic development during childhood and adolescence. Child and Adolescent Psychiatric Clinics of North Americian 13:529-549.

Savin-Williams, R.C., and Diamond, L.M. (2000) Sexual identity trajectories among sexual-minority youth: gender comparisons. Archives of Sexual Behavior 29:419-440.

Savin-Williams, R.C., and Diamond, L.M. (2004) Sex. In: Lerner, R.M., and Steinberg, L. (eds) Handbook of adolescent psychology, 2nd ed. John Wiley, New York, pp. 189-231.

Savin-Williams, R.C., and Ream, G.L. (2003) Suicide attempts among sexualminority male youth. Journal of Clinical Child Adolescent Psychology 32:509522.

Schneider, M.S. (2001) Toward a reconceptualization of the coming-out process for adolescent females. In: D'Augelli, A.R., and Patterson, C.J. (eds) Lesbian, gay, and bisexual identities and youth: psychological perspectives. Oxford University Press, New York, pp. 71-96.

Sears, J.T. (1991) Growing up gay in the South: race, gender, and journeys of the spirit. Harrington Park Press, New York.

Sell, R.L., Wells, J.A., and Wypij, D. (1995) The prevalence of homosexual behavior and attraction in the United States, the United Kingdom and France: results of national population-based samples. Archives of Sexual Behavior 24:235-248.

Storms, M.D. (1981) A theory of erotic orientation development. Psychological Review 88:340-353.

Tartagni, D. (1978) Counseling gays in a school setting. School Counselor 26:26-32. 
Troiden, R.R. (1979) Becoming homosexual: a model of gay identity acquisition. Psychiatry 42:362-373.

Van Griensven, F., Kilmarx, P.H., Jeeyapant, S., Manopaiboon, C., Korattana, S., Jenkins, R.A., Uthaivoravit, W., Limpakarnjanarat, K., and Mastro, T.D. (2004) The prevalence of bisexual and homosexual orientation and related health risks among adolescents in northern Thailand. Archives of Sexual Behavior 33:137-147.

Wiederman, M.W. (1999) Volunteer bias in sexuality research using college student participants. Journal of Sex Research 36:59-66.

Weinberg, M.S., Williams, C.J., and Pryor, D.W. (1994) Dual attraction: understanding bisexuality. Oxford University Press, New York. 